Energy

Volume 167 Issue EN1

The implications of upstream emissions

from the power sector

Hammond and O'Grady
Proceedings of the Institution of Civil Engineers Energy 167 February 2014 Issue EN1 Pages 9-19 http://dx.doi.org/10.1680/ener.13.00006 Paper 1300006

Received 26/04/2013 Accepted 15/08/2013

Keywords: environment/power stations (fossil fuel)/ Kustainability
seywords: i ice

\title{
The implications of upstream emissions from the power sector
}

Geoffrey P. Hammond

Professor, Department of Mechanical Engineering and Institute for

Sustainable Energy and the Environment (1.SEE), University of Bath, Bath, UK
Áine O'Grady

Research Officer, Department of Mechanical Engineering, University of Bath, Bath, UK

Upstream environmental burdens arise from the need to expend energy resources in order to extract and deliver fuel to a power station or other users. They include the energy requirements for extraction, processing/refining, transport and fabrication, as well as methane leakages from coal mining activities - a major contribution - and natural gas pipelines. The upstream carbon dioxide emissions associated with various power generators and UK electricity transition pathways towards a 'low carbon' future have been evaluated on a 'whole systems' basis. Carbon dioxide capture facilities coupled to fossil-fuelled plants are shown, for example, to deliver only a $70 \%$ reduction in greenhouse gas emissions (including both upstream and operational emissions), in contrast to the normal presumption of a $\mathbf{9 0 \%}$ saving. In addition, the present UK greenhouse gas trajectories associated with transition pathways to $\mathbf{2 0 5 0}$ are found to differ significantly from those produced by the British government's Department of Energy and Climate Change and its independent Committee on Climate Change. These bodies do not currently account for upstream, 'fugitive' greenhouse gas emissions. Therefore, there will actually remain further emissions upstream that are unaccounted for, even if the current UK carbon dioxide equivalent reduction targets are apparently met.

\section{Introduction}

\subsection{Background}

Electricity generation contributes a large proportion of the total greenhouse gas (GHG) emissions in the UK, due to the predominant use of fossil fuel (coal and natural gas) inputs. Indeed, the various power sector technologies (fossil fuel plants with and without carbon dioxide capture and storage (CCS), nuclear power stations, and renewable energy technologies (available on a large and small, or domestic, scale)) all involve differing environmental impacts and other risks. However, 'carbon footprints' have become the 'currency' of debate in a climate-constrained world. They represent the amount of carbon dioxide (or carbon dioxide equivalent $\left(\mathrm{CO}_{2} \mathrm{e}\right)$ ) emissions associated with a given activity or community, and are generally presented in terms of units of mass or weight (kilograms per functional unit (e.g. $\mathrm{kgCO}_{2} \mathrm{e} / \mathrm{kWh}$ )). The UK government therefore established an independent Committee on Climate Change (CCC) under the Climate Change Act of 2008 in order to advise it on progress towards meeting its overall carbon reduction target of $80 \%$ by 2050 from heating, power and transport fuels against a 1990 baseline. A new approach was thereby adopted to managing and responding to climate change in the UK, and led to the creation of legally binding budgets for reducing Britain's GHG emissions. The CCC thus proposed to tighten its second and third carbon budgets progressively (CCC, 2010 ) to a $37 \%$ emissions reduction by 2020 (relative to 1990), followed by reductions from 2010 to 2030 of $46 \%$. In parallel, the $\mathrm{CCC}$ advocated deep cuts in power sector emissions through the 2020s (CCC, 2010), with UK electricity generation becoming largely decarbonised by 2030-2040. Anderson et al. (2008) have argued that such long-term targets do not have a firm scientific basis, and they instead examined UK cumulative emission pathways that would be required to help ensure that global mean surface temperatures do not exceed $2^{\circ} \mathrm{C}$ above preindustrial levels. They suggested that industrialised countries must radically and urgently curtail their energy demands (Anderson et al., 2008) in order to stabilise mean surface temperatures in line with the needs for only $2{ }^{\circ} \mathrm{C}$ of global warming.

A consortium of partners from nine British university institutions was established (Hammond and Pearson, 2013) with research funding provided under the auspices of a strategic partnership between E.On UK (the electricity generator) and the UK Engineering and Physical Sciences Research Council (EPSRC) to study 'transition pathways' to a more electric future for the United Kingdom of Great Britain and Northern Ireland (UK). They adopted the Dutch transitions approach (see, for example, Geels, 2002; Rip and Kemp, 1998; Verbong 
The implications of upstream

emissions from the power

sector

Hammond and O'Grady and Geels, 2010) and a time horizon to 2050. The UK team devised three energy transition pathways that were distinguished by their governance structures: driven by the market, central government intervention and local community initiative, respectively. A framework was developed whereby the descriptions or 'narratives' associated with these pathways underwent technological elaboration with quantitative underpinning provided by a range of different economic and technical models (Hammond and Pearson, 2013). In addition, the 'whole systems' energy and environmental performance of these UK electricity transition pathways was evaluated by Hammond et al. (2013) on a 'life-cycle' basis. Both energy analysis and environmental lifecycle assessment (LCA) were employed to constitute a 'whole systems' approach to the UK energy system (Figure 1). Energy analysis required estimates of the energy outputs of the power generators during use, and the energy requirements for their construction and operation. In contrast, LCA studies produce estimates of a wider range of pollutants or wastes released into the environment as a consequence of the power network. Upstream environmental burdens arise from the need to expend energy resources in order to deliver, for example, fuel to a power station. They include the energy requirements for extraction, processing/refining, transport and fabrication, as well as methane leakage that occurs in coal mining activities - a major contribution - and from natural gas pipelines. Therefore, 'whole systems' GHG emissions, equal upstream GHG emissions plus operational GHG emissions, when the 'operational' or 'stack' emissions are those directly associated with the combustion of fossil fuels within power stations. These whole systems emissions amount to those related to the 'energy transformation system' as defined by Slesser (1978); see again Figure 1 (Hammond, 2000). The impact of upstream, particularly 'fugitive', emissions on the carbon performance of various low carbon technologies (such as large-scale combined heat and power (CHP) plants and CCS) and the pathways distinguish these findings, which differ significantly from those of other UK analysts.

A few months after the publication of the study by Hammond et al. (2013), the CCC launched a report that contained (among other things) the findings of its own study of life-cycle emissions of low carbon and conventional energy technologies, including various power generators (for which the first author $(\mathrm{GPH})$ was a member of the relevant CCC peer review panel, alongside industry representatives) (CCC, 2013). This indicated that low carbon power generation technologies, such as nuclear power and renewable energy technologies, all exhibit a significant emissions savings in comparison to their fossil fuel equivalents on a life-cycle basis. They found that fossil fuel (coal and natural gas) power plants with CCS provide much lower emissions than conventional stations without carbon

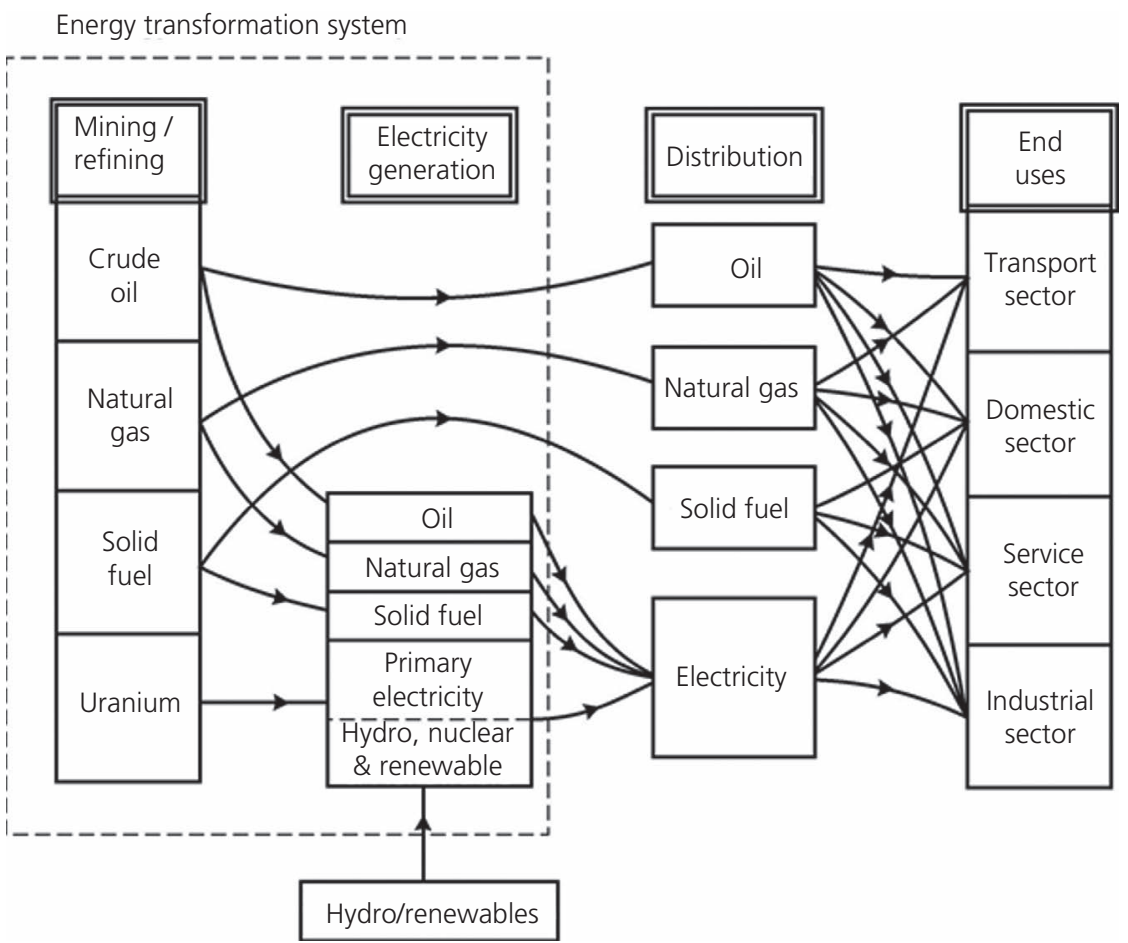

Figure 1. A simplified representation of the UK energy system (source: Hammond, 2000) 
Energy

Volume 167 Issue EN1
The implications of upstream

emissions from the power

sector

Hammond and O'Grady dioxide capture, but both were much higher than those associated with low carbon technologies. Coal CCS also displayed considerably greater emissions than those arising from gas CCS. Consequently, the CCC argued that CCS stations should only be employed as part of a portfolio of low carbon power generators, with preference given to gas CCS and, potentially, biomass CCS. In quantitative terms these findings are similar to those of Hammond et al. (2013) and the present study. However, the CCC have not as yet accounted for upstream, fugitive emissions in their modelling studies of UK $\mathrm{CO}_{2} \mathrm{e}$ emission trajectories over their various carbon budget periods or to the ultimate $80 \%$ reduction target set for 2050 .

\subsection{The issues considered}

Three transition pathways for a more electric future on to 2050 (Foxon et al., 2010) have been evaluated here in terms of their life-cycle energy and environmental performance. These are similar to the estimates made by Hammond et al. (2013) relating to version 1.1 of the pathways, but the present research examined the most recent version 2.1. This second iteration of the pathway narratives (Foxon, 2013) was used to identify the changes that might be expected in how end-users consume electricity according to the logic of each pathway: driven by the market, central government intervention and local community initiatives, respectively. The Transition Pathways Consortium's technical elaboration working group (Hammond and Pearson, 2013) then quantified the resulting power demands to meet domestic, commercial, industrial and transport energy end-uses (see Figure 1), as well as the consequent supply requirements and generator capacity to 2050 . The present study has therefore been based around the appraisal of energy use and $\mathrm{CO}_{2} \mathrm{e}$ emissions associated with version 2.1 of the transition pathways. An integrated, life-cycle approach has again been used (Allen et al., 2008; Hammond et al., 2013). Thus, the techniques of both energy analysis and environmental LCA were applied on a 'whole systems' basis. The focus here is on the implications of upstream, particularly fugitive, $\mathrm{CO}_{2}$ e emissions in relation to the power generators (including the consequences for the adoption of CCS facilities in the power sector) and the modelling of future UK electricity projections on to around 2050. This work forms part of an ongoing research effort aimed at evaluating and optimising the performance of various sustainable energy systems (see, for example, Allen et al., 2008; Hammond, 2011; Hammond et al., 2011, 2013) in the context of transition pathways to a low carbon future for the UK (Alderson et al., 2012; Foxon et al., 2010).

\section{Energy analysis and carbon accounting on a life-cycle basis}

\subsection{Methods}

In order to determine the primary energy inputs needed to produce a given amount of product or service, it is necessary to trace the flow of energy through the relevant industrial system (Allen et al., 2008; Hammond and Winnett, 2006; Udo de Haes and Heijungs, 2007). This idea is based on the first law of thermodynamics, that is, the principle of conservation of energy, or the notion of an energy balance applied to the system. It leads to the technique of first law or 'energy' analysis, sometimes termed 'fossil fuel accounting', which was developed in the 1970s in the aftermath of the oil crisis (see, for example, Roberts (1978) or Slesser (1978)). There are several different methods of energy analysis (see Figure 2); the principal ones being statistical analysis, input-output table analysis and process analysis (Allen et al., 2008; Roberts, 1978; Slesser, 1978). The first method is limited by the available statistical data for the whole economy or a particular industry, as well as the level of its disaggregation. Statistical analysis often provides a reasonable estimate of the primary energy cost of products classified by industry. However, it cannot account for indirect energy requirements or distinguish between the different outputs from the same industry (Roberts, 1978). The technique of input-output table analysis, originally developed by economists (Hammond and Jones, 2008), can also be utilised to determine indirect energy inputs. This approach is constrained only by the level of disaggregation that is available in national input-output tables. Process energy analysis is the most detailed of the methods, and is usually applied to a particular process or industry, requiring process flow-charting. More recently, hybrid methods using a combination of inputoutput and process energy analysis have been developed (see, for example, Hammond et al., 2013).

Energy analysis preceded LCA and as such they share much of the same fundamental methodology. In order to evaluate the environmental consequences of a product or activity the impact resulting from each stage of its life-cycle must be considered. This led to the development of ecotoxicology, or a study of the harmful effects of releasing chemicals into the environment, and a range of analytical techniques that now come under the 'umbrella' of LCA. The aim of the LCA is often to identify opportunities for environmental improvement by detecting the areas with the most significant impacts (Hammond et al., 2013). In the present study, the focus has been on carbon accounting, rather than the wider range of environmental burdens examined by Hammond et al. (2013), who determined 17 separate impact indicators, as well as a tentative 'single score' aggregate LCA metric.

\subsection{System boundaries}

The system boundary in energy analysis should strictly encompass the energy resource in the ground (e.g. oil in the well or coal at the mine - the 'cradle'), although this is sometimes taken as the national boundary in practice (see again Figure 1). Analysis is ideally performed over the entire life-cycle of the product or activity, 'from cradle to grave'. 
The implications of upstream

emissions from the power

sector

Hammond and O'Grady

Levels of regression

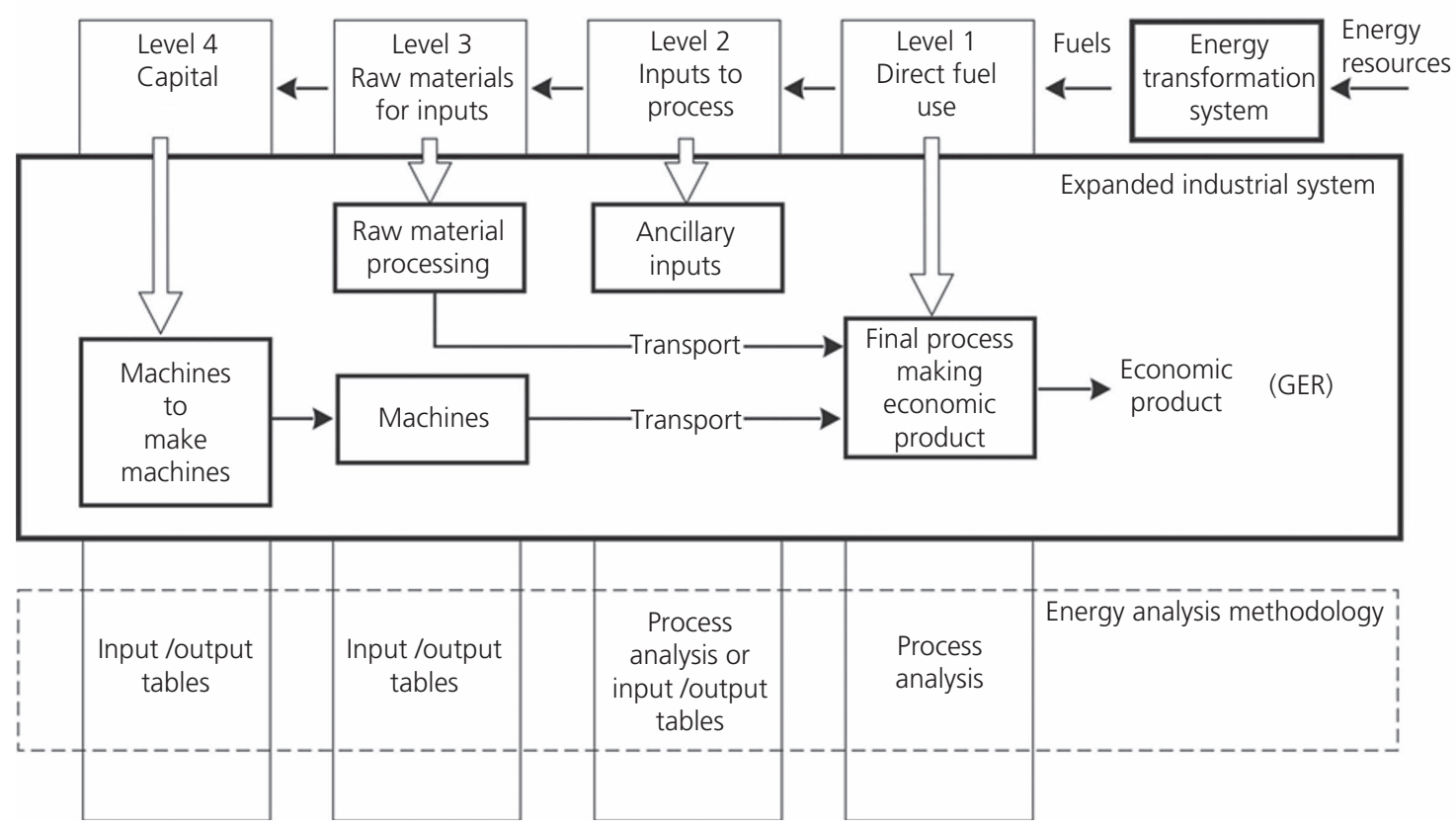

Figure 2. Schematic representation of the energy analysis process (source: Allen et al., 2008; adapted from Slesser, 1978). GER, gross energy requirement

Different 'levels of regression' may be employed (Slesser, 1978), depending on the extent to which feedback loops are accounted for, or the degree of accuracy desired (see Figure 2). Thus, the sum of all the outputs from this system multiplied by their individual energy requirements must be equal to the sum of inputs multiplied by their individual requirements. The process consequently implies the identification of feedback loops, such as the indirect, or 'embodied', energy requirements for materials and capital inputs. In a full LCA, the energy and materials used, and pollutants or wastes released into the environment as a consequence of a product or activity, are quantified over the whole life-cycle; again 'from cradle to grave' (see Heijungs et al., 1992; Udo de Haes and Heijungs, 2007). However, detailed 'end-of-life' (i.e. decommissioning and waste recycling) information is rarely available on which to carry out a complete analysis. Life-cycle analysis often involves activities that are geographically diverse; that is, the energy and material inputs to a product or service may be drawn from any continent or geopolitical region of the world.

Embodied energy and carbon appropriate to the various UK power generators were determined by Hammond et al. (2013) using proprietary LCA software tools and databases, together with the 'Inventory of Carbon and Energy (ICE)' (developed at the University of Bath (Hammond and Jones, 2008, 2011)).
Embodied energy and carbon dioxide emissions of the various technologies are based on real-life data compiled from current power plants. In the case of more novel technologies (e.g. wind and wave), proxy datasets have been tailored based on leading studies of this technology. These impacts have been averaged per kWh over the entire life-cycle of the plant to allow both current and future plants to be compared on a like-by-like basis at any given time. Current technology data have been assumed for future plants due to the uncertainty in technology improvements into the future.

'Embodied energy' is here defined as the total primary energy consumed from direct and indirect processes associated with power production and within a system boundary defined as 'cradle to gate' (Hammond and Jones, 2011). This includes upstream activities from material extraction (quarrying/ mining), manufacturing, transportation, fabrication processes and construction of the power plant. The most significant upstream impact is due to fugitive emissions arising from methane leakages that occur in coal mining activities and from natural gas pipelines. In the present study, the downstream boundary is effectively taken as the point of electricity end-use: mainly in the home, by the commercial service provider, or in the factory. Similarly, 'embodied carbon' is the sum of fuel-related carbon dioxide emissions (i.e. embodied energy 


\begin{tabular}{|c|c|c|c|}
\hline Fuel & $\begin{array}{l}\text { Defra }{ }^{a} \text { GHG emissions factor from } \\
\text { combustion of fuel: } \mathrm{kg} \mathrm{CO}_{2} \mathrm{e} / \mathrm{kWh}\end{array}$ & $\begin{array}{l}\text { GHG emissions from upstream } \\
\text { activities: } \mathrm{kg} \mathrm{CO} \mathrm{CO}_{2} \mathrm{e} / \mathrm{kWh}\end{array}$ & Resulting ratio (increase) \\
\hline Coal & $0 \cdot 330$ & $0 \cdot 060$ & $6 \cdot 5: 1(+18 \%)$ \\
\hline Natural gas & $0 \cdot 204$ & 0.041 & $5 \cdot 0: 1(+20 \%)$ \\
\hline
\end{tabular}

aData source: the UK Department for Environment, Food and Rural Affairs (Defra) - UK National Atmospheric Emissions Inventory (NAEI) maintained by Ricardo-AEA (see http://naei.defra.gov.uk/)

Table 1. Upstream GHG emissions from fossil fuels (source:

Hammond et al., 2013). $\mathrm{CO}_{2} \mathrm{e}$, carbon dioxide equivalent; $\mathrm{GHG}$,

greenhouse gas

that is combusted, but not the feedstock energy that is retained within materials) and process-related carbon dioxide emissions (Hammond and Jones, 2011). Adding operational or 'stack' emissions effectively results in all the emissions right through to the delivery of electricity to the consumer. This might then be thought of as a 'cradle to consumer (or end-user)' system boundary or 'whole systems' emissions.

\section{Upstream emissions from power plants}

The operational (direct or stack) emissions associated with the combustion of fuels are compared with GHG emission associated with upstream coal and natural gas activities in Table 1. These data indicate the magnitude of the difference between direct combustion and upstream emissions. Such fugitive GHG emissions, for example, arise from the production and transport of natural gas. They imply that the measures advocated by the CCC for decarbonising the UK economy, viewed by some as challenging, are actually likely to be not stringent enough. The resulting impacts are highly variable depending on the source of gas; whether, for example, they come from UK natural gas fields or are imported into Britain from the Russian Federation. The gas CCS dataset interrogated here is the same as the transition pathways version 1.1 gas dataset, apart from an assumption of a $90 \%$ carbon dioxide capture rate and a 15\% energy penalty (Hammond et al., 2011). GHG emissions associated with the distribution of Russian gas were found to be 20 times those from UK sources (Hammond et al., 2013). The latter consequently exhibits very low pipeline GHG emissions, compared to Russian gas. The high impact of Russian gas production and distribution is mainly due to their higher gas leakage in piping, together with longer transmission distances. These upstream GHG emissions also have significance in terms of analysing the three transition pathways, because UK indigenous natural gas supplies are uncertain; notwithstanding the possibility of obtaining shale gas by means of hydraulic fracturing (or 'fracking'). The reserves to production ratio of UK natural gas fields is currently about 51, whereas that for the world as a whole is approximately 631 (Hammond,
2011). Geological estimates of recoverable UK shale gas reserves are, in any case, in their infancy and vary widely.

CCS facilities coupled to fossil-fuelled power plants provide a climate change mitigation strategy that potentially permits the continued use of fossil fuels while reducing the carbon dioxide emissions. However, the present study has indicated (see Table 2) that coal CCS is about two-thirds lower in terms of GHG emissions in comparison with conventional coal-fired plant (without CCS); that is, a fall from 1.09 to $0.31 \mathrm{~kg}$ carbon dioxide equivalent per $\mathrm{kWh}$. Thus, carbon dioxide capture is likely to deliver only a $70 \%$ reduction in carbon dioxide emissions on a whole systems basis (including both upstream and operational emissions), in contrast to the normal presumption of a $90 \%$ saving (Hammond et al., 2013). This brings into question the attractiveness of coal CCS as an environmental proposition. Nevertheless, it is a relatively cheap fuel, which is readily available (from the UK and elsewhere), and provides flexible generation in contrast to new nuclear power (see, for example, Hammond, 2011). Consequently, there is a broader range of factors to consider when selecting new UK power generation capacity.

Industrial companies have argued that carbon dioxide capture facilities may only be built for natural gas power stations, because of the cheaper capital cost compared to a supercritical coal plant (especially as the plant is likely to operate at 'midmerit', rather than baseload). Biomass co-firing with CCS may, of course, mitigate upstream emissions on a full life-cycle basis, due to potential 'negative emissions' (Kruger and Darton, 2013); something that needs careful study in the future. CHP - whether coal or natural gas fired - uses one energy input, but two energy outputs: heat and power. Carbon dioxide emissions therefore need to be allocated or partitioned on some basis between these so-called 'co-products'. This can be achieved on the basis of energy, exergy or economic value (Hammond et al., 2013). These different treatments will yield varying results for this technology and the various future projections. CHP is a 'carbon-heavy' technology that is likely to provide a large contribution to the 
The implications of upstream

emissions from the power

sector

Hammond and O'Grady

Coal

Grid average, 1990

Table 2. Power technologies in ranked order by 'whole systems' GHG (upstream plus operational or 'stack') emissions (source: adapted from Hammond et al., 2013). CCS, carbon capture and storage; $\mathrm{CO}_{2} \mathrm{e}$, carbon dioxide equivalent; $\mathrm{GHG}$, greenhouse gas

UK carbon profile going forward towards 2050. CHP contributes substantially in all three pathways, especially under a decentralised, 'civil society' driven regime (termed the 'thousand flowers pathway') as can be seen in Figure 3.

\section{Upstream emissions from more electric transition pathways}

A number of reputable studies have been undertaken in recent years that yield low or zero carbon energy scenario sets for the UK. These include those produced by the British Government's Department of Energy and Climate Change
(DECC) (the DECC 2050 calculator; see DECC, 2010), the UK Energy Research Centre (UKERC) (the UKERC Energy 2050 project; see Skea et al., 2010), the Tyndall Centre for Climate Change Research (Mander et al., 2008) and the Centre for Alternative Technology (CAT) (the Zero Carbon Britain 2030 project; see CAT, 2010). They all enable insights to be drawn regarding the realism of each projection, and reflect a range of aspirations from those wishing to achieve 2050 carbon reduction targets ( $80 \%$ in the case of DECC and UKERC), to that of completely decarbonising Britain by 2030 (CAT). The five Tyndall decarbonisation scenarios (Mander et al., 2008)

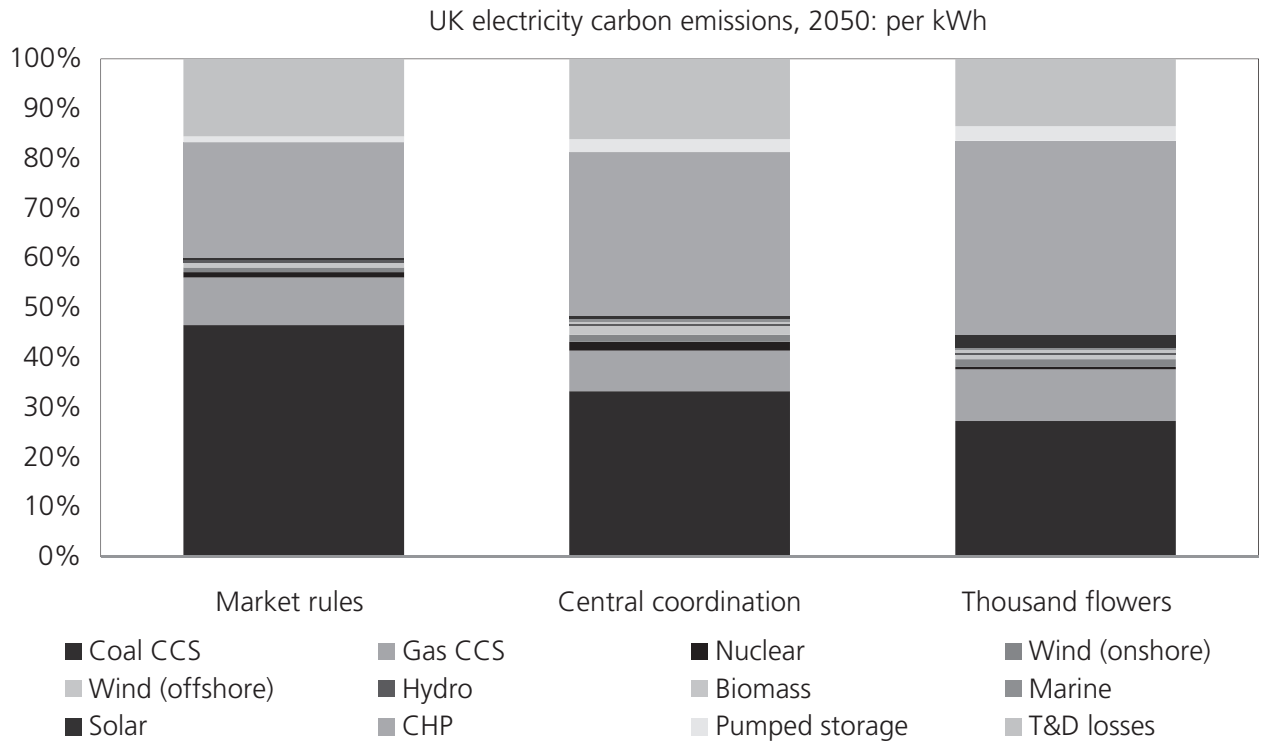

Figure 3. Power generator shares of the UK 'whole systems' carbon intensity $\left(\mathrm{kg} \mathrm{CO}_{2} \mathrm{e} / \mathrm{kWhe}\right)$ in 2050 under each of the three transition pathways - version 2.1. CCS, carbon capture and storage; $\mathrm{CHP}$, combined heat and power; $\mathrm{CO}_{2} \mathrm{e}$, carbon dioxide equivalent; T\&D, transmission and distribution 
The implications of upstream

emissions from the power

sector

Hammond and O'Grady were focused on an earlier $60 \%$ carbon reduction target for 2050, although they employ a distinctive 'backcasting' approach generated and reviewed with the aid of stakeholders. On the other hand, the DECC 2050 calculator is basically an engineering-based, Excel spreadsheet model that is open source and arguably transparent. The tool permits users to select their own combination of technologies to achieve an $80 \%$ reduction in GHG emissions by 2050, while ensuring that energy supply and demand are balanced. The UKERC Energy 2050 project (Skea et al., 2010) involved a four-scenario core set that was underpinned by a cost-optimisation model (UK Markal). It took "an eclectic approach to scenario building" with a backcasting dimension to achieve a combination of UK energy resilience and climate change mitigation (Skea et al., 2010). In contrast, the Zero Carbon Britain 2030 project (CAT, 2010) examines how to 'power down' radically UK heat and electricity demand - what they viewed as 'high carbon living' through the adoption of a combination of new technology, efficient design across the economy and motivating behavioural change, while 'powering up' the use of renewables to supply the residual energy requirements. The selection of an appropriate energy scenario or pathways set is rather arbitrary for the current purposes of illustrating the implications of upstream emissions on the power sector. The focus of the present study is therefore on the three pathways developed by the Transition Pathways Consortium (funded by the E.OnEPSRC strategic partnership). It consisted of UK engineers, social scientists, policy analysts and innovation specialists, and included both the present authors.

The Transition Pathways Consortium sought to develop and explore three 'transition pathways' towards a UK low carbon electricity system (Foxon et al., 2010; Hammond and Pearson, 2013), to understand the changing roles of large and small 'actors' in the dynamics of these transitions, and to learn from the successes and failures of past transitions. They have focused on the choices and actions needed to 'get there from here', and on the analysis of the pathways' technical, socioeconomic and environmental implications. An innovative, arguably robust, and 'whole systems' evidence base was developed that is distinctive from those devised elsewhere in the UK energy research community in its focus on governance structures. The pathways are not predictions or roadmaps; rather they are a way of imaginatively exploring future possibilities, to inform proactive and protective decision-making and enhance the potential for building consensus towards common goals.

An initial set of transition pathways for a UK low carbon energy system were developed by applying three main steps (Foxon et al., 2010): characterising the existing energy regime, its internal tensions and landscape pressures on it; identifying dynamic processes at the niche level; and specifying interactions giving rise to or strongly influencing transition pathways (see Figure 4).
They were devised by means of stakeholder workshops (involving UK energy researchers, industrialists, and policy advisers and decision-makers), a narrative descriptive of each pathway, and their subsequent technical elaboration. Stakeholder workshops were employed by the consortium to distinguish the logics of three core sets of actors: driven by the market, central government intervention and local community initiative, respectively. Consequently, the three transition pathways were named market rules (MR), central coordination (CC) and thousand flowers (TF); each being dominated by a single group's logic. Hammond and Pearson (2013) summarise the development and high-level analysis of the version 2.1 transition pathways set, in order to explain their key features and the distinctiveness and value of the approach; the approach builds among other things on approaches originally devised by Dutch researchers (e.g. Geels, 2002; Rip and Kemp, 1998; Verbong and Geels, 2010). The consortium thus applied a multi-level perspective for analysing sociotechnical transitions, based on interactions at and between three levels: niche innovations, sociotechnical regimes and macro-landscape pressures (see Figure 4 (Foxon et al., 2010)).

The development of the UK transition pathways has undergone several iterative loops. Earlier whole systems appraisal by Hammond et al. (2013) related to version 1.1 of the pathways. However, a second iteration of these pathways was performed in order to investigate the weaknesses of that version in terms of technical feasibility, electric grid enhancement needs, social acceptability, energy and environmental performance, and also in light of outcomes for stakeholders' workshops (Foxon, 2013). Based on the logic of the three pathways, using a bottom-up approach, the change of energy use was determined, and the demand by sector was modelled (Barton et al., 2013). The progression of the electricity mix required to meet the demand, while adhering to the logic of the given pathway, was then projected (Barnacle et al., 2013). Version 2.1 also enabled the pathways to be updated in order to incorporate further stakeholder inputs and developments in UK energy policy.

In the study by Hammond et al. (2013) version 1.1 of the pathways (Foxon et al., 2010) was evaluated in terms of their energy and environmental performance. Subsequently, following the development of version 2.1 of the pathways, a similar study was carried out and is reported here that adopted the same methodology. Earlier studies of the carbon and environmental footprints of low carbon UK energy futures (by, e.g., Alderson et al., 2012) suggest that refinements of the technical elaboration or quantification of the pathways are unlikely to make significant differences to their environmental impacts reported. In this present study, similar trends were observed in both iterations, although version 2.1 suggests greater decarbonisation by 2050 . There are many GHGs, and each has a different potency. Each of a basket of six 'Kyoto' gases is 
The implications of upstream

emissions from the power

sector

Hammond and O'Grady

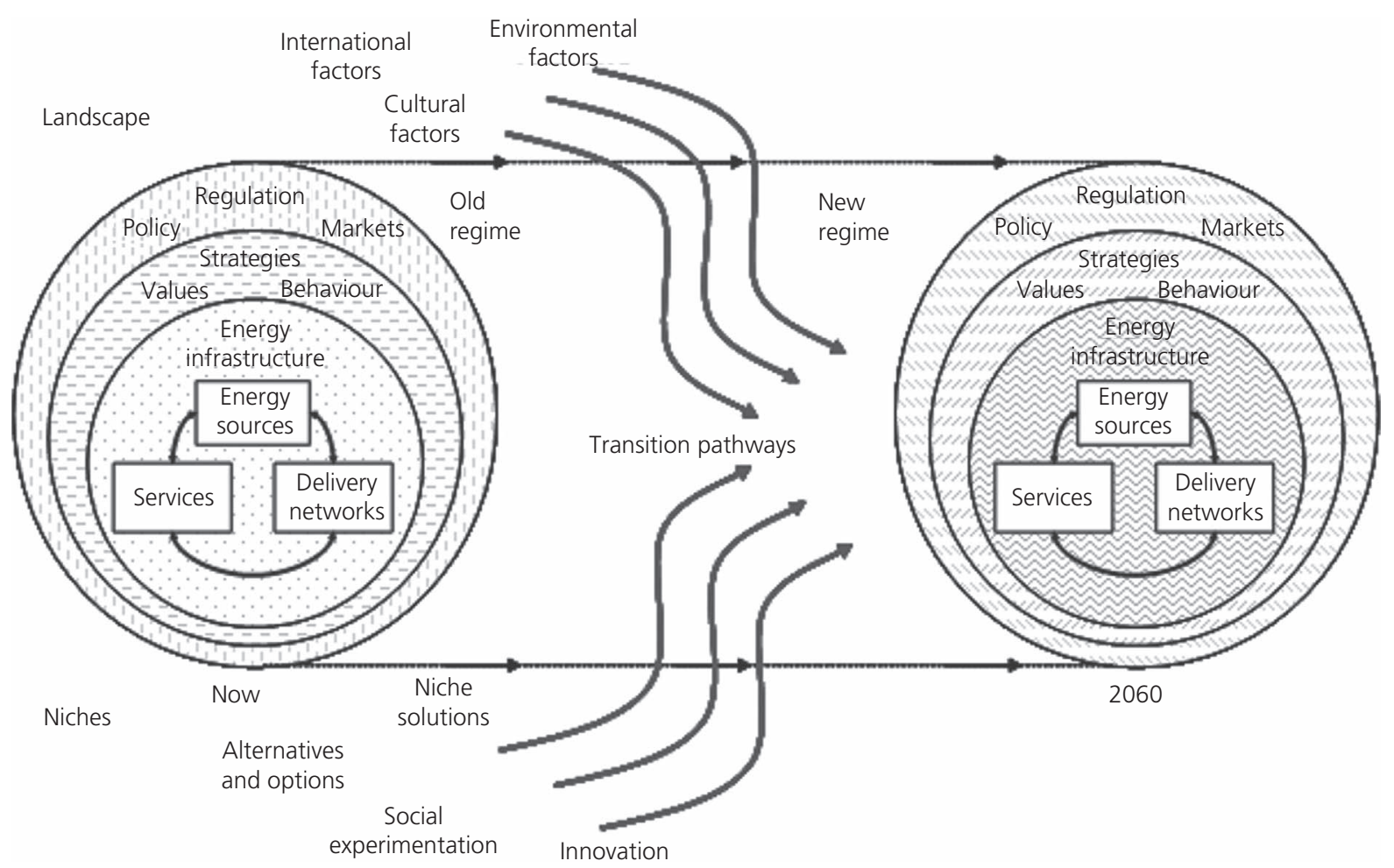

Figure 4. Possible transition pathways and the factors that influence them (source: the Transition Pathways Consortium (Foxon et al., 2010))

normalised relative to the impact of one unit of carbon dioxide (IPCC, 2007), the main contributor to climate change. They are typically expressed in terms of 'carbon dioxide equivalents', with units of $\mathrm{kgCO}_{2} \mathrm{e}$, where e denotes equivalents. Projected 'whole systems' carbon dioxide emissions (i.e. operational or 'stack', plus upstream emissions) from the UK electricity supply industry (Mt $\mathrm{CO}_{2} \mathrm{e}$ ) under all three version 2.1 transition pathways over 1990 2050 are shown in Figure 5. In contrast, the power generator shares of the UK carbon intensity ( $\mathrm{kg} \mathrm{CO}_{2} \mathrm{e} / \mathrm{kWhe}$ ) in 2050 under each of the version 2.1 pathways are illustrated in Figure 3. The coal CCS share of emissions is seen to fall significantly from the MR pathway through $\mathrm{CC}$ to its lowest value for $\mathrm{TF}$. Its dominance is largely replaced by CHP generation. Nuclear power plays the more significant role in carbon dioxide reductions under the CC pathway. Large-scale renewables have a major influence by 2050 under the $\mathrm{CC}$ pathway and, in particular, the TF pathway (see again Figure 3). Similar trends were seen in version 1.1 with minor changes made to key technologies, especially in the TF pathway. Coal CCS has less dominance under version 2.1, while gas CCS, wind and nuclear power share increased in both the MR and CC pathways. In contrast, the role of coal CCS, gas CCS and nuclear power was reduced in the TF pathway, and replaced mainly by CHP.
The present version 2.1 transition pathways (see, for example, Figure 5) suggest that, taking account of upstream emissions, there might actually be a fall in carbon dioxide emissions from the UK power generation sector of some $31-51 \%$ by 2020 , 65 $86 \%$ by 2030 and $78-93 \%$ in 2050 . The lower figures relate to the MR pathway, while the higher figures are associated with the TF pathway. The CCC advocated deep cuts in power sector operational emissions through the 2020s (CCC, 2010), with UK electricity generation largely decarbonised by 2030-2040. In contrast, the present transition pathways (see again Figure 5) projections indicate that the UK electricity supply industry could not be fully decarbonised by 2050 on the "whole systems' basis employed in the current study (see Figure 1). This is because the present estimates take account of upstream, fugitive GHG emissions, whereas the projections by bodies such as the CCC and DECC do not. Nevertheless, the transition pathways suggest that the electricity supply industry will be able to bear a significant share of the overall $80 \%$ carbon reduction target by 2050 . The CCC analysis suggests that their projections would lead to average operational emissions from generation falling to approximately $50 \mathrm{gCO}_{2} /$ $\mathrm{kWhe}$ by 2030 . In contrast, the present MR pathway (Figure 3) indicates that 'whole system' emissions from the UK electricity 


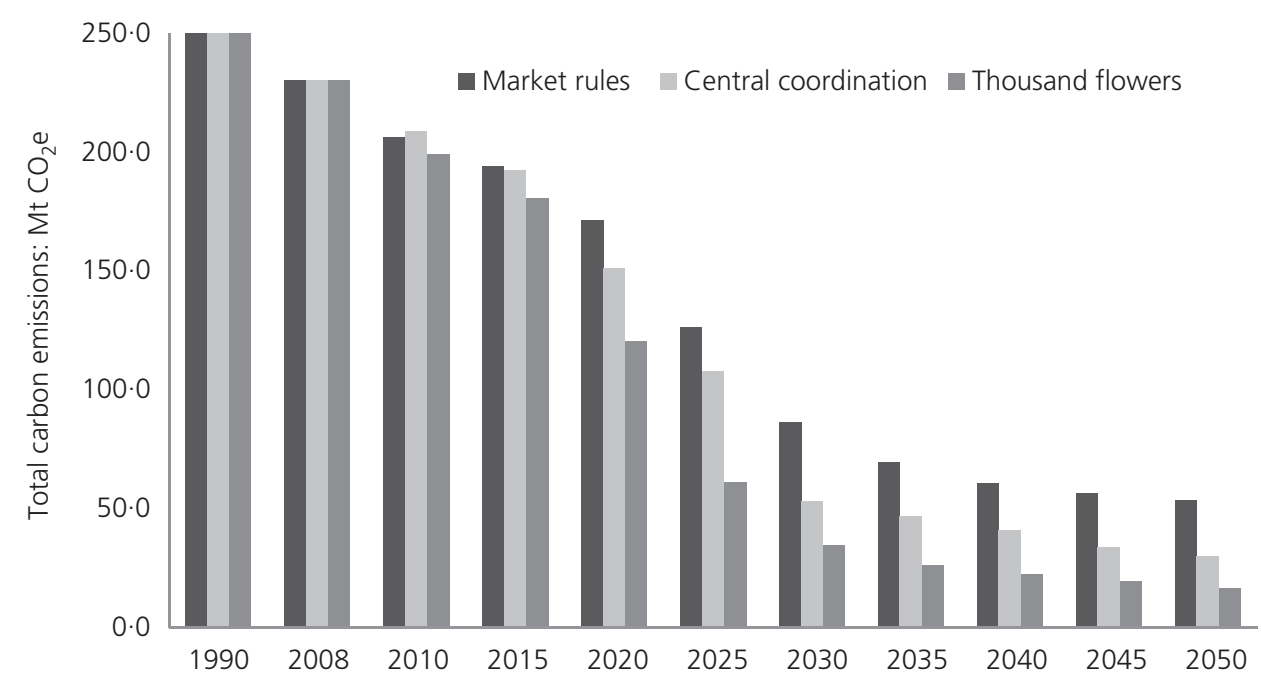

Figure 5. Projected UK 'whole systems' carbon dioxide emissions from the electricity sector $\left(\mathrm{Mt} \mathrm{CO}_{2} \mathrm{e}\right)$ 1990-2050 under the three transition pathways - version 2.1. $\mathrm{CO}_{2} \mathrm{e}$, carbon dioxide equivalent; ESI, electricity supply industry

supply industry are likely to fall, accounting for upstream emissions, to only approximately $202 \mathrm{gCO}_{2} \mathrm{e} / \mathrm{kWhe}$ by 2030 and approximately $105 \mathrm{gCO}_{2} \mathrm{e} / \mathrm{kWhe}$ by 2050 . Even the least impactful pathway, $\mathrm{TF}$, indicates emissions falling to only approximately $108 \mathrm{gCO}_{2} \mathrm{e} / \mathrm{kWhe}$ by 2030 and approximately 53 $\mathrm{gCO}_{2} \mathrm{e} / \mathrm{kWhe}$ by 2050 .

\section{Conclusions}

An integrated approach was recently used by Hammond et al. (2013) to assess the impact of version 1.1 of three UK transition pathways (Foxon et al., 2010; Hammond and Pearson, 2013). They employed both energy analysis and LCA, applied on a 'whole systems' basis: from 'cradle to consumer'. This highlighted the significance of upstream (particularly fugitive) emissions, in contrast to power plant operational or 'stack' emissions, as well as their technological and policy implications. The findings were reinforced by the carbon and environmental footprint analysis of Alderson et al. (2012), who examined the environmental impacts associated with UK power generation based on historic data and a set of three alternative energy scenarios to 2050. They found that their projections indicated that the UK electricity supply industry could only be near-decarbonised by 2050 under various low carbon scenarios. This is because their environmental footprint estimates also took account of upstream emissions (i.e. those associated with what is termed the 'embodied energy' footprint component). Here the most recent
UK transition pathways (version 2.1) have been appraised, again on a whole systems basis.

The emissions reductions achieved from power plants fitted with carbon dioxide capture technology may not be as high as many suggest. There is no doubt that having a CCS plant is better than having one without CCS, but in order to get realistic estimates of how attractive they are going to be, account must be taken of upstream emissions. Incorporating the emissions from mining (and the 'fugitive' methane emissions that escape as a result), as well as the average penalties for processing, transportation and facility construction, combined with the emissions once the feedstock is combusted, it was found that the carbon dioxide capture rate was significantly lower than that typically presumed. The study by Hammond et al. (2013) thus indicated that coal CCS is about two-thirds lower in terms of GHG emissions in comparison with conventional coal-fired plant (without CCS), a fall from 1.09 to $0.31 \mathrm{~kg}$ carbon dioxide equivalent per $\mathrm{kWh}$. Carbon dioxide capture facilities are therefore likely to deliver only about a $70 \%$ reduction in carbon dioxide emissions on a whole system basis (including both upstream and operational emissions), in contrast to the normal presumption of a $90 \%$ reduction. The failure to include upstream emissions not only impacts the environmental performance of electricity as demonstrated here, but many goods and services across the UK. Decarbonisation policies 
The implications of upstream

emissions from the power

sector

Hammond and O'Grady may lead to a shift in practices and production that migh produce unintended negative environmental effects upstream that remain unaccounted for.

The present results for life-cycle $\mathrm{CO}_{2} \mathrm{e}$ emissions from various power generators, and the earlier ones of Hammond et al. (2013), are similar to those obtained from the recent study commissioned by the CCC (CCC, 2013). The CCC argue as a result that CCS power stations should only be employed as part of a portfolio of low carbon power generators (CCC, 2013), with preference given to gas CCS and, potentially, biomass CCS. Obviously, a 70\% reduction in carbon dioxide emissions due to power plant CCS is a significant gain in terms of climate change mitigation, although Hammond et al. (2013) noted that coal CCS may not be all that much more attractive than unabated natural gas. This is especially the case when one takes into account the health and environmental impacts of coal-linked pollution, such as particulate matter and mercury. The findings of Hammond et al. (2013) have attracted international media interest, including in the USA (see, for example, the report by the journalist Tamar Hallerman in the online GHG Monitor) (Hallerman, 2013).

Finally, if governments are serious about meeting stringent GHG emissions reduction targets, like the aim to cut carbon dioxide emissions in the UK to $80 \%$ below 1990 levels by midcentury, they will need to account for the fact that emission savings stemming from particular technologies may not be as high as many predict. Neither the UK government's DECC (DECC, 2010) nor its independent CCC (CCC, 2010) currently account fully for upstream, fugitive GHG emissions in their projections of carbon dioxide pathways towards the legally binding emissions reduction target on to 2050. They neglect, in particular, methane leakages that occur in coal mining activities - a major contribution - and from natural gas pipelines. The CCC, for example, have not as yet accounted for upstream emissions in their modelling studies of UK carbon dioxide equivalent emission trajectories over their various carbon budget periods or on to the ultimate $80 \%$ reduction target set for 2050. If the UK government is genuine in its desire to meet its challenging $\mathrm{CO}_{2}$ e reduction targets, then it will be necessary to account for upstream, fugitive emissions from power plants. Otherwise, there will actually remain further emissions upstream that are unaccounted for, even if the current UK carbon dioxide reduction targets are apparently met. Thus, upstream emissions provide a drag on our ability to deliver on meaningful global warming targets in the $\mathrm{UK}$ and the wider world.

\section{Acknowledgements}

This work is part of a programme of research at the University of Bath on the technology assessment of low carbon energy systems and transition pathways that is supported by a series of
UK research grants and contracts awarded by various bodies. In the present context, the first author (GPH) is jointly leading a large consortium of university partners funded by the UK Engineering and Physical Sciences Research Council entitled 'Realising transition pathways: whole systems analysis for a UK more electric low carbon energy future' (under grant EP/ F022832/1). The second author (AO'G) is wholly funded by this grant. Both authors are grateful for the interaction with other members of the consortium (and its predecessor) made up of participants from nine UK universities. However, the views expressed here are those of the authors alone, and do not necessarily reflect the views of the collaborators or the policies of the funding body. The authors' names are listed alphabetically.

\section{REFERENCES}

Alderson H, Cranston GR and Hammond GP (2012) Carbon and environmental footprinting of low carbon UK electricity futures to 2050. Energy 48(1): 96-107.

Allen SR, Hammond GP, Harajli HA et al. (2008) Integrated appraisal of micro-generators: methods and applications. Proceedings of the Institution of Civil Engineers - Energy 161(2): 73-86, http://dx.doi.org/10.1680/ener.2008.161.2.73

Anderson K, Bows A and Mander S (2008) From long-term targets to cumulative emission pathways: reframing UK climate policy. Energy Policy 36(10): 3714-3722.

Barnacle M, Robertson E, Galloway S, Barton J and Ault G (2013) Modelling generation and infrastructure requirements for transition pathways. Energy Policy 52: 60-75, http://www. sciencedirect.com/science/journal/03014215/52

Barton J, Huang S, Infield D et al. (2013) The evolution of electricity demand and the role for demand side participation, in buildings and transport. Energy Policy 52: $85-102$, http://www.sciencedirect.com/science/journal/ $03014215 / 52$

CAT (Centre for Alternative Technology) (2010) Zero Carbon Britain 2030: A New Energy Strategy. CAT Publications, Machynlleth, Powys, UK.

CCC (Committee on Climate Change) (2010) The Fourth Carbon Budget: Reducing Emissions Through the 2020s. CCC, London, UK.

CCC (2013) Reducing the UK's Carbon Footprint and Managing Competitiveness Risks. CCC, London, UK.

DECC (Department of Energy and Climate Change) (2010) 2050 Pathways Analysis. DECC, London, UK.

Foxon TJ (2013) Transition pathways for a UK low carbon electricity future. Energy Policy 52: 10-24, http://www. sciencedirect.com/science/journal/03014215/52

Foxon TJ, Hammond GP and Pearson PJ (2010) Developing transition pathways for a low carbon electricity system in the UK. Technological Forecasting and Social Change 77(8): 1203-1213.

Geels FW (2002) Technological transitions as evolutionary 
The implications of upstream

emissions from the power

sector

Hammond and O'Grady reconfiguration processes: a multi-level perspective and a case-study. Research Policy 31(8-9): 1257-1274.

Hallerman T (2013) Study: total emissions reductions from CCS likely 70\%, not 90\%. GHG Reduction Technologies Monitor 8(6), http://ghgnews.com/index.cfm/study-total-emissionsreductions-from-ccs-likely-70-not-90/ (accessed 01/02/2013).

Hammond GP (2000) Energy, environment and sustainable development: a UK perspective. Trans IChemE Part B: Process Safety and Environmental Protection 78(4): 304-323. Hammond GP (2011) Nuclear power in the twenty-first century. In Handbook of Sustainable Energy (Galarraga I, González-Eguino M and Markandya A (eds)). Edward Elgar, Cheltenham, UK, Chapter 16, pp. 331-356.

Hammond GP and Jones Cl (2008) Embodied energy and carbon in construction materials. Proceedings of the Institution of Civil Engineers - Energy 161(2): 87-98, http://dx.doi.org/ 10.1680/ener.2008.161.2.87

Hammond GP and Jones Cl (2011) Embodied Carbon: The Inventory of Carbon and Energy (ICE) (Lowrie F and Tse P (eds)). A BSRIA Guide - BG 10/2011, BSRIA Ltd., Bracknell, UK.

Hammond GP and Pearson PJG (2013) Challenges of the transition to a low carbon, more electric future: from here to 2050 (Editorial). Energy Policy 52: 1-9, http://www. sciencedirect.com/science/journal/03014215/52

Hammond GP and Winnett AB (2006) Interdisciplinary perspectives on environmental appraisal and valuation techniques. Proceedings of the Institution of Civil Engineers Waste and Resource Management 159(3): 117-130, http://dx. doi.org/10.1680/warm.2006.159.3.117

Hammond GP, Ondo Akwe SS and Williams S (2011) Technoeconomic appraisal of fossil-fuelled power generation systems with carbon dioxide capture and storage. Energy 36(2): 975-984.

Hammond GP, Howard HR and Jones $\mathrm{Cl}$ (2013) The energy and environmental implications of UK more electric transition pathways: a whole systems perspective. Energy Policy 52: 103-116, http://www.sciencedirect.com/science/journal/ $03014215 / 52$

Heijungs R, Guinee JB, Huppes G et al. (1992) Environmental Life-cycle Assessment of Products - Guide and Background. Report CML 92, Leiden University, Leiden, The Netherlands.

Intergovernmental Panel on Climate Change (IPCC) (2007) Climate Change 2007 - The Physical Science Basis, Cambridge University Press, Cambridge, UK.

Kruger T and Darton R (2013) Negative emissions technologies could become the world's largest industry. Proceedings of the Institution of Civil Engineers - Civil Engineering 166(2): 51, http://dx.doi.org/10.1680/cien.2013.166.2.51

Mander SL, Bows A, Anderson KL et al. (2008) The Tyndall decarbonisation scenarios - Part I: Development of a backcasting methodology with stakeholder participation. Energy Policy 36(10): 3754-3763.

Rip A and Kemp R (1998) Technological change. In Human Choices and Climate Change: Vol. 2 (Rayner S and Malone EL (eds)). Battelle Press, Columbus, Ohio, USA.

Roberts F (1978) The aims, methods and uses of energy accounting. Applied Energy 4(1): 199-217.

Skea J, Ekins P and Winskel M (eds) (2010) Energy 2050: Making the Transition to a Secure Low Carbon Energy System for the UK. Earthscan/James \& James, London, UK.

Slesser M (1978) Energy in the Economy. Macmillan Press, London, UK.

Udo de Haes HA and Heijungs R (2007) Life-cycle assessment for energy analysis and management. Applied Energy 84(7-8): 817-827.

Verbong GPJ and Geels FW (2010) Exploring sustainability transitions in the electricity sector with socio-technical pathways. Technological Forecasting \& Social Change 77(8): 1214-1221.

\section{WHAT DO YOU THINK?}

To discuss this paper, please email up to 500 words to the editor at journals@ice.org.uk. Your contribution will be forwarded to the author(s) for a reply and, if considered appropriate by the editorial panel, will be published as discussion in a future issue of the journal.

Proceedings journals rely entirely on contributions sent in by civil engineering professionals, academics and students. Papers should be 2000-5000 words long (briefing papers should be 1000-2000 words long), with adequate illustrations and references. You can submit your paper online via www.icevirtuallibrary.com/content/journals, where you will also find detailed author guidelines. 